\title{
Preparation and Properties of MCT Ceramics for RF and THz Applications
}

\author{
Zhaoxian Xiong*, Zhangzhao Weng*, Jinbao Huang*, Bin Yang*, R. Donnan*, Haixue Yan and M.J. Reece \\ *Department of Materials Sciece and Engineering, Xiamen University, Xiamen 361005, China

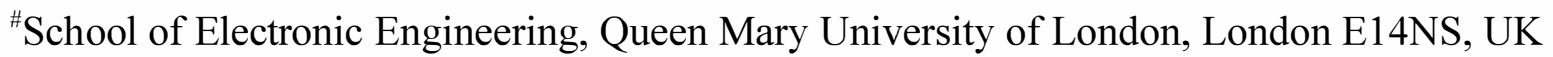 \\ School of Engineering and Material Sciences, Queen Mary University of London, London E1 4NS, UK \\ *Email: zxxiong@xmu.edu.cn
}

\begin{abstract}
Dielectric ceramics of $0.95 \mathrm{MgTiO}_{3}-0.05 \mathrm{CaTiO}_{3}$ were prepared via a solid-state reaction method. It is evident that high permittivity and low loss are correlated to high density and high purity in the $\mathrm{THz}$ frequency domain. Best dielectric properties were obtained for samples sintered at $1260{ }^{\circ} \mathrm{C}$, which is attributable to their high density and high purity. However, the dielectric properties of the ceramics deteriorated when sintered above $1260{ }^{\circ} \mathrm{C}$, which is attributed to the significantly increased content of second phase produced by 'over' sintering.
\end{abstract}

Index Terms - Dielectric ceramics, THz application, resonators, filters.

\section{INTRODUCTION}

In the past ten years, Terahertz $(\mathrm{THz})$ technology has demonstrated extraordinary prospects due to its attractive applications in material, chemical, communication and life ciences [1-5]. Portable, low loss and light weighted $\mathrm{THz}$ devices are developed, for example sensors [6], resonators [7] and filters [8], to accelerate applications of $\mathrm{THz}$ technologies. However, the lack of advanced materials in the $\mathrm{THz}$ band is a major limited factor. Although obvious progress has been achived in the reliable measurement systems to test dielectric properties of materials in the $\mathrm{THz}$ band $[9,10]$, systematic study on the materials with suitble dielectric properties was rarely reported. $\mathrm{MgTiO}_{3}$, chemically a rhombohedral structure with space group R3c [11], is a popular microwave material which displays a relatively low permittivity $\left(\varepsilon_{\mathrm{r}}=17\right)$, high quality factor $(\mathrm{Qf}=160,000$ at $7 \mathrm{GHz})$ and negative temperature coefficient of resonant frequency $\left(\mathrm{T}_{\mathrm{f}}=50 \mathrm{ppm} /{ }^{\circ} \mathrm{C}\right.$ ) [12]. Beside a high permittivity and quality factor, a near-zero temperature coefficient of resonant frequency is also demanded for commercial applications. It is found that with a small addition of $5 \mathrm{~mol}^{\%} \mathrm{CaTiO}_{3}$ (orthorhombic structure with space group $\mathrm{Pbnm}$ ) to the samples produces improved permittivity (21), quality factor $(\mathrm{Qf}=56,000$ at $7 \mathrm{GHz})$ and near zero $T_{f}$ [12]. It is reported that $\mathrm{MgTiO}_{3}$ and $\mathrm{CaTiO}_{3}$ do not react into solid solutions but separate phases due to the different crystal structures [13]. In this paper, $0.95 \mathrm{MgTiO}_{3}-$ $0.05 \mathrm{CaTiO}_{3}$ ceramics, i.e., MCT, were prepared under different sintering conditions. The effects of density, phase purity and microstructure on the dielectric properties of the samples were investigated in the $\mathrm{THz}$ spectral domain.

\section{EXPERIMENTAL PROCEDURES}

Ceramics of $0.95 \mathrm{MgTiO}_{3}-0.05 \mathrm{CaTiO}_{3}$ were prepared via a conventional solid-state reaction route, with chemical reagents of $\mathrm{MgO}(\mathrm{CP}, 99 \%), \mathrm{CaCO}_{3}(\mathrm{CP}, 99 \%)$ and $\mathrm{TiO}_{2}(\mathrm{CP}, 99 \%)$. The reagents were firstly weighed based on the stoichiometry of $0.95 \mathrm{MgTiO}_{3}-0.05 \mathrm{CaTiO}_{3}$. The mixed powder was then calcined at $1150{ }^{\circ} \mathrm{C}$ for $2 \mathrm{~h}$ with $1 \mathrm{wt} \%$ of $\mathrm{ZnO}$ added as a sintering aid. Green bodies were pressed and sintered at different temperatures, $1240{ }^{\circ} \mathrm{C}, 1260{ }^{\circ} \mathrm{C}, 1280{ }^{\circ} \mathrm{C}$ and $1300{ }^{\circ} \mathrm{C}$ for $3 \mathrm{~h}$ in air, respectively.

The crystal structures of the samples were identified with X-ray diffraction (XRD) using $\mathrm{CuK}_{a}$ radiation (X'pert PRO, Panalytical, Holand). The microstructure of the specimens was observed by a scanning electron microscope (SEM, TM-3000, Hitachi, Japan). Element analysis was carried out with Energy-Dispersive X-ray spectroscopy (EDX, Oxford instrument). Densities were obtained using the Archimedes' method. Microwave dielectric properties of the ceramics, including $\varepsilon_{\mathrm{r}}$, Qf and $\mathrm{T}_{\mathrm{f}}$, were measured with the parallel plate resonator method connected with a vector network analyzer (VNA) at $8.2 \mathrm{GHz}$. The $\mathrm{THz}$ dielectric behavior of the samples between $0.22 \mathrm{THz}$ and $0.32 \mathrm{THz}$ were measured using a VNA2-driven quasi-optical transmission meter [14].

\section{RESULTS AND DISCUSSION}

The density of ceramics sintered at $1240{ }^{\circ} \mathrm{C}, 1260{ }^{\circ} \mathrm{C}$, $1280{ }^{\circ} \mathrm{C}$ and $1300{ }^{\circ} \mathrm{C}$ were determined to be $3.778 \mathrm{~g} / \mathrm{cm}^{3}$, $3.790 \mathrm{~g} / \mathrm{cm}^{3}, 3.790 \mathrm{~g} / \mathrm{cm}^{3}$ and $3.790 \mathrm{~g} / \mathrm{cm}^{3}$, respectively. The apparent density increased with increasing sintering temperature and a near constant density was achieved for samples sintered above $1260{ }^{\circ} \mathrm{C}$. The XRD patterns of dense ceramics sintered at $1260{ }^{\circ} \mathrm{C}, 1280{ }^{\circ} \mathrm{C}$ and $1300{ }^{\circ} \mathrm{C}$ are shown in Fig. 1. The samples are multi-phase, with a main crystal phase of $\mathrm{MgTiO}_{3}$ (JCPDS $¥ 79-0831$ ), and minor ones of $\mathrm{CaTiO}_{3}$ (JCPDS $\# 22-0153$ ) and $\mathrm{MgTi}_{2} \mathrm{O}_{5}$ (JCPDS $\# 76-2673$ ). In Fig. $1, \mathrm{MgTi}_{2} \mathrm{O}_{5}$ is indexed in the $\mathrm{XRD}$ for $1300{ }^{\circ} \mathrm{C}$, $\mathrm{MgTiO}_{3}$ is indexed for $1280{ }^{\circ} \mathrm{C}$ and $\mathrm{CaTiO}_{3}$ is indexed for $1260{ }^{\circ} \mathrm{C}$. The formation of the impurity phase $\mathrm{MgTi}_{2} \mathrm{O}_{5}$ is 
possibly resulted from the decomposition of $\mathrm{MgTiO}_{3}$ [15]. With increasing sintering temperature, $\mathrm{MgO}$ maybe partially dissolved in the near region of grain boundary [15]. Therefore, the XRD peak intensity of $\mathrm{MgTi}_{2} \mathrm{O}_{5}$ increased with increasing sintering temperature. It is reported that $\mathrm{MgTi}_{2} \mathrm{O}_{5}$ could not be fully eliminated when ceramics were prepared using conventional sintering [16]. Here, the amount of $\mathrm{ZnO}$ and $\mathrm{MgO}$ is too small to be detected by XRD.

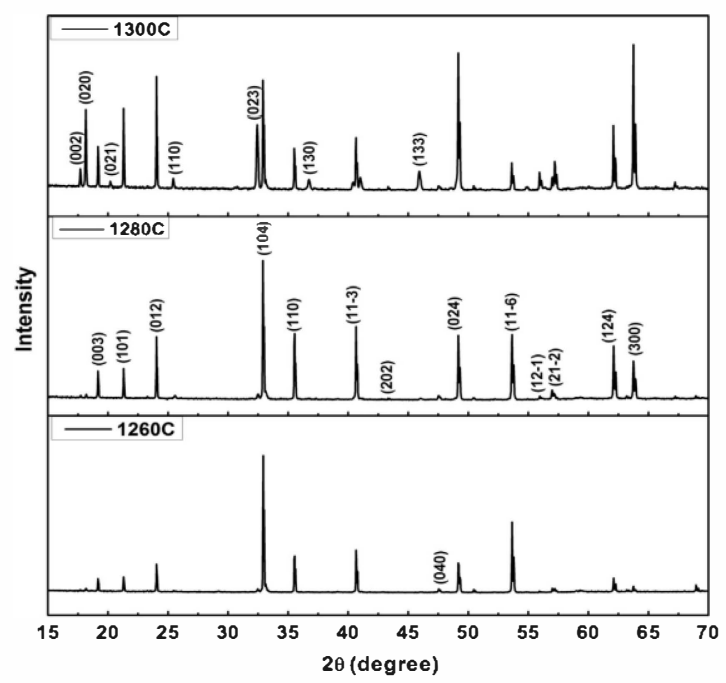

Fig. 1 XRD patterns of ceramics sintered at $1260{ }^{\circ} \mathrm{C}, 1280{ }^{\circ} \mathrm{C}$ and $1300{ }^{\circ} \mathrm{C}$ for $3 \mathrm{~h}$. Here, $\mathrm{MgTi}_{2} \mathrm{O}_{5}$ is indexed for $1300{ }^{\circ} \mathrm{C}, \mathrm{MgTiO}_{3}$ is for $1280{ }^{\circ} \mathrm{C}$, and $\mathrm{CaTiO}_{3}$ is only for $1260{ }^{\circ} \mathrm{C}$.

Three different shapes of grains were observed in the ceramics sintered from $1260{ }^{\circ} \mathrm{C}$ to $1300{ }^{\circ} \mathrm{C}$ for $3 \mathrm{~h}$. An SEM image in addition to EDX analysis, of the ceramic sintered at $1280{ }^{\circ} \mathrm{C}$ is demonstrated in Fig. 2. According to the semiquantitative molar ratio of $\mathrm{Mg} / \mathrm{Ti}$ and $\mathrm{Ca} / \mathrm{Ti}$, the big blockshaped grains(1) were identified as $\mathrm{MgTiO}_{3}$ due to a $\mathrm{Mg} / \mathrm{Ti}$ ratio (0.97) of about 1:1. The small square block- shape grains(2) were identified as $\mathrm{CaTiO}_{3}$ due to a $\mathrm{Ca} / \mathrm{Ti}$ ratio (0.96) of about 1:1. Moreover, the small bar-shaped grains(3) were identified as a $\mathrm{MgTi}_{2} \mathrm{O}_{5}$ due to $\mathrm{Mg} / \mathrm{Ti}$ ratio (0.52) of about 1:2.

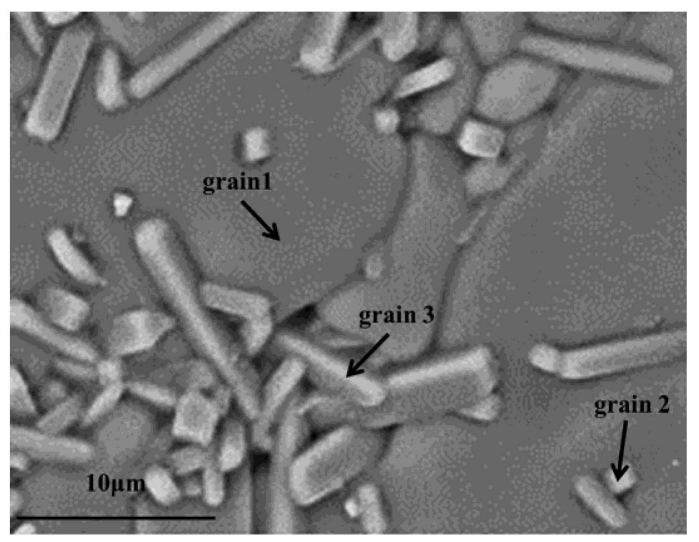

Fig. 2 SEM image of ceramic sintered at $1280{ }^{\circ} \mathrm{C}$ for $3 \mathrm{~h}$.
The microwave dielectric properties at $8.2 \mathrm{GHz}$ for ceramics sintered at different temperatures are revealed in Fig. 3. The improvement of microwave dielectric properties for samples sintered from $1240{ }^{\circ} \mathrm{C}$ to $1260{ }^{\circ} \mathrm{C}$ for $3 \mathrm{~h}$ is attributed to the increase of the density. The maximum value of $\mathrm{Qf}=91,238 \mathrm{GHz}$ (at $8.2 \mathrm{GHz}$ ) and $\varepsilon_{\mathrm{r}}=20.5$ were obtained for the ceramic sintered at $1260{ }^{\circ} \mathrm{C}$. The grain size increases with increasing sintering temperature so that the total area of the grain boundary is reduced, leading to an increase of the quality factor. However, the permittivity and Qf for samples sintered above $1260{ }^{\circ} \mathrm{C}$ both decreased. The reason for this is probably due to the increasing second phase content, as identified by XRD and SEM analysis, rather than agrain size effect in the dense samples. The sample sintered at $1240{ }^{\circ} \mathrm{C}$ was eliminated from the $\mathrm{THz}$ investigation because of its low density and low permittivity. According to the algorithm in the work of Yang et al. [9], dielectric properties (permittivity and loss tangent) can be obtained through complex transmission spectra of ceramics measured over abroad band frequency domain, i.e. $0.22 \mathrm{THz}$ to $0.32 \mathrm{THz}$. The permittivity of ceramics sintered at $1260{ }^{\circ} \mathrm{C}, 1280{ }^{\circ} \mathrm{C}$ and $1300{ }^{\circ} \mathrm{C}$ for $3 \mathrm{~h}$ were around 18, exhibiting minimal dispersion. The dielectric losses of the samples varied significantly from 0.0019 (sintered at $1260{ }^{\circ} \mathrm{C}$ ) to 0.0072 (sintered at $1300{ }^{\circ} \mathrm{C}$ ) at $0.22 \mathrm{THz}$ as displayed in Fig. 4. This indicates that the $\mathrm{MgTi}_{2} \mathrm{O}_{5}$ second phase had a obvious influence on the increase of loss not only in the microwave frequency domain [17] but also in the THz frequency domain (Fig. 4).

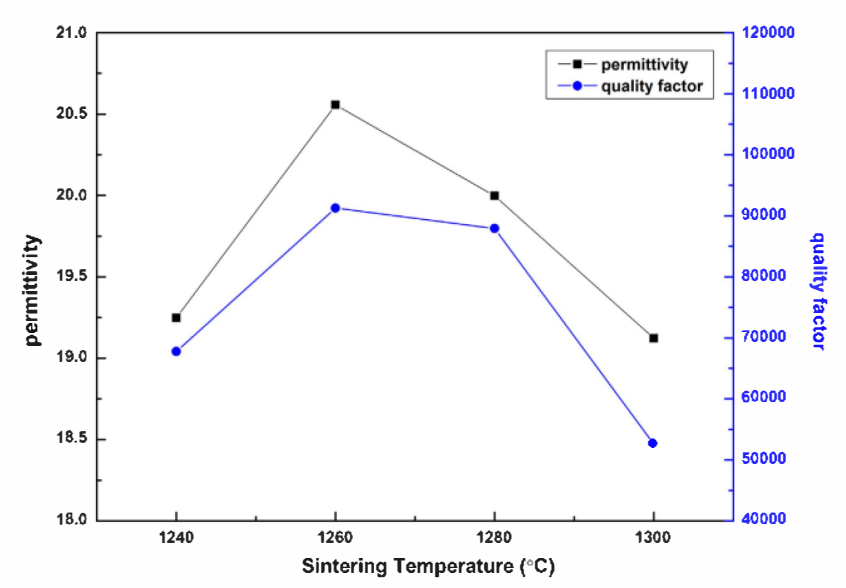

Fig. 3 Dielectric properties at $8.2 \mathrm{GHz}$ of ceramics sintered at $1240{ }^{\circ} \mathrm{C}, 1260{ }^{\circ} \mathrm{C}, 1280{ }^{\circ} \mathrm{C}$ and $1300{ }^{\circ} \mathrm{C}$ for $3 \mathrm{~h}$. 

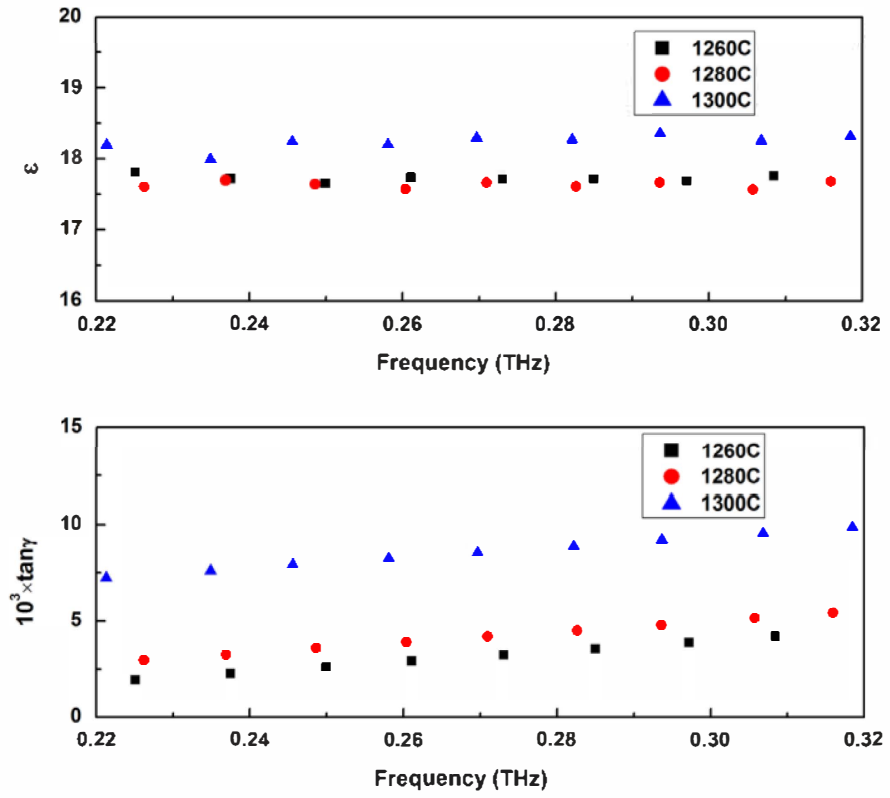

Fig. 4 Calculated permittivity (top) and loss tangent (bottom) of ceramics sintered at $1260{ }^{\circ} \mathrm{C}, 1280{ }^{\circ} \mathrm{C}$ and $1300{ }^{\circ} \mathrm{C}$ for $3 \mathrm{~h}$ in the frequency range $0.22 \mathrm{THz}$ to $0.32 \mathrm{THz}$.

\section{CONCLUSION}

Dielectric ceramics of $0.95 \mathrm{MgTiO}_{3}-0.05 \mathrm{CaTiO}_{3}$ were prepared via a solid-state reaction method. Best dielectric properties were achived for samples sintered at $1260{ }^{\circ} \mathrm{C}$ for $3 \mathrm{~h}$, which is attributable to their high density and high purity. However, the dielectric properties of the samples deteriorated when sintered above $1260{ }^{\circ} \mathrm{C}$. This is attributed to the significantly increased content of second phase due to 'over' sintering of samples. It is evident that high permittivity and low loss are correlated to high density and high purity in the $\mathrm{THz}$ frequency domain.

\section{ACKNOWLEDGEMENT}

The authors would like to thank the Engineering and Physical Sciences Research Council (EPSRC) of UK for financial support under Grant EP/I014845, and, Fujian Provincial Department of Science and Technology of China for financial support under Grant No. 2013H6020.

\section{REFERENCES}

[1] B. Ferguson, X.C. Zhang, "Materials for Terahertz Science and Technology," Nat. Mater., vol.1, pp.26-33, 2002.

[2] AI McIntosh, B.Yang, S.M. Goldup, M. Watkinson, R.S. Donnan, "Terahertz Spectroscopy: a Powerful New Tool for the Chemical Sciences? ", Chem. Soc. Rev., vol.41, pp. 2072-2082, 2012.

[3] J.H. Son, "Terahertz electromagnetic interactions with biological matter and their applications," J. Appl. Phys., vol.105, pp:102033, 2009.
[4] P.Weightman, "Prospects for the study of biological systems with high power sources of terahertz radiation," Phys. Biol., vol. 9, pp:053001, 2012.

[5] S. Koenig, D. Lopez-Diaz, J. Antes, F. Boes, R. Henneberger, A. Leuther, et al, "Wireless sub-THz communication system with high data rate," Nat. Photonics,vol. 7, pp: 977-981, 2013.

[6] M. Nagel, M. Först, H. Kurz, "THz biosensing devices: fundamentals and technology," J. Phys. Condens. Matter., vol.18, pp: S601, 2006.

[7] I. Al-Naib, C. Jansen, M. Koch, "Thin-film sensing with planar asymmetric metamaterial resonators," Appl. Phys. Lett., vol. 93, pp: 083507, 2008.

[8] Y. Zhu, S.Vegesna, V. Kuryatkov, M. Holtz, M. Saed, A.A. Bernussi, "Terahertz bandpass filters using double-stacked metamaterial layers," Opt. Lett., vol. 37, pp:296-298, 2012.

[9] B. Yang, R.J. Wylde, D.H. Martin, P. Goy, R.S. Donnan, S. Caroopen, "Determination of the gyrotropic characteristics of hexaferrite ceramics from 75 to 600GHz," IEEE Trans. Microwave Theory Tech., vol.58, pp:3587-3597, 2010.

[10] A. Tomasino, A. Parisi, S. Stivala, P. Livreri, A. Cino, A. Busacca, et al., "Wide band $\mathrm{THz}$ time domain spectroscopy based on optical rectification and electro-optic sampling," Sci. Rep., pp:3, 2013.

[11] B.A. Wechsler, R. VonDreele, "Structure refinements of $\mathrm{Mg} 2 \mathrm{TiO} 4, \mathrm{MgTiO} 3$ and MgTi2O5 by time-of-flight neutron powder diffraction," Acta. Crystallogr., Sect B: Struct. Sci., vol.45, pp:542-549, 1989.

[12] V. Ferreira, F. Azough, R. Freer, J. Baptista, "The effect of $\mathrm{Cr}$ and $\mathrm{La}$ on $\mathrm{MgTiO} 3$ and $\mathrm{MgTiO} 3-\mathrm{CaTiO} 3$ microwave dielectric ceramics", J. Mater. Res.,; vol.12, pp:3293-3299, 1997.

[13] Y.C. Liou, W.C. Tsai, S.L.Yang, "Synthesis of 0.95MgTiO3$0.05 \mathrm{CaTiO} 3$ ceramics by reaction-sintering," The proceedings of the $16^{\text {th }}$ international conference on composite materials.

[14] Y. Wang, B. Yang, Y. Tian, R.S. Donnan, M.J. Lancaster, "Micromachined thick mesh filters for millimeter-wave and terahertz applications", IEEE Trans. Terahertz Sci. Tech., vol.4, pp:247-253, 2014.

[15] H.K. Shin, H. Shin, S.Y. Cho, K.S. Hong, "Phase evolution and dielectric properties of $\mathrm{MgTiO}-\mathrm{CaTiO} 3$ - based ceramic sintered with lithium borosilicate glass for application to low temperature co - fired ceramics", J. Am. Ceram. Soc., vol.88, pp:2461-2465, 2005.

[16] X. Zhou, Y. Yuan, L. Xiang, Y. Huang, "Synthesis of MgTiO3 by solid state reaction and characteristics with addition", $J$. Mater. Sci., vol.42, pp:6628-6632, 2007.

[17] C.L. Huang, C.L. Pan, S.J. Shium, "Liquid phase sintering of MgTiO3-CaTiO3 microwave dielectric ceramics", Mater. Chem. Phys., vol.78, pp:111-115, 2003. 